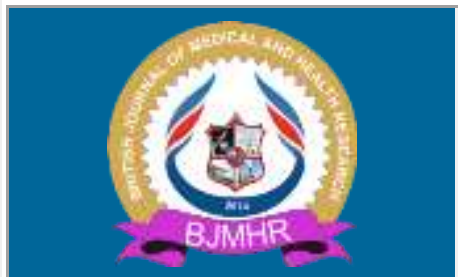

\title{
BJMHR
}

British Journal of Medical and Health Research Journal home page: www.bjmhr.com

\section{Primary Hyperparathyroidism Presenting With Mandibular Brown Tumor As First Clinical Manifestation}

\author{
Mandeep Sagar GT $^{1 *}$, Parul Dutta ${ }^{1}$ \\ 1. Department of Radio-Diagnosis, Gauhati Medical college Hospital, Guwahati, Assam, \\ India. 781032.
}

\begin{abstract}
Brown tumor also known as osteitis fibrosa cystica generalisata or Von Recklinghausen's disease of bone, is a metabolic bone disease that develops in primary, secondary or tertiary hyperparathyroidism. Brown tumors can occur in any location but are most common in the ribs, clavicle and pelvis. The reported prevalence of brown tumors is $3 \%$ in primary hyperparathyroidism and can occur in mandible very rarely [1]. We describe an unusual case of primary hyperparathyroidism in a 30-year-old female patient presenting with mandibular brown tumor as the first clinical manifestation. It should be differentiated from other true giant cell tumors of bone.
\end{abstract}

Keywords: Brown tumour, primary hyperparathyroidism, parathyroid adenoma, mandible. 


\section{INTRODUCTION}

A 30-year-old female patient presented to the department of general surgery of our institute, complaining of a large swelling over the left jaw, of two months duration. She had mobility of the left lower teeth and also complained of difficulty in chewing food on left side, occasional bone pains over right hand and also hip pain. On detailed history eliciting it was learnt that patient was also depressed since past few months. Past history: Patient had undergone open cholecystectomy for Cholelithiasis, 6 years ago and her family history, past medical history was insignificant.

\section{Investigations}

A routine skeletal survey revealed multiple bone involvement; hence a metabolic etiology was suspected and hormonal analysis and other blood biochemistry was advised which showed raised alkaline phosphates and parathyroid hormone levels of $1534 \mathrm{pg} / \mathrm{ml}(\mathrm{N}: 12-65 \mathrm{pg} / \mathrm{ml})$. Serum calcium level was high - 18.6mg/dl (N: 8.5-10.5 ml/dl), Vitamin D levels were very low. Other blood parameters were within normal limits.

Ultrasonography of neck was performed, which revealed normal thyroid gland with a welldefined soft tissue lesion just adjacent and inferior to left lobe of thyroid gland. FNAC from the neck lesion was suggestive of parathyroid neoplasia. Parathyroid scintigraphy $\left({ }^{9 \mathrm{~m}} \mathrm{Tc}\right.$ Sestamibi SPECT) was done, which confirmed the diagnosis of parathyroid neoplasia.

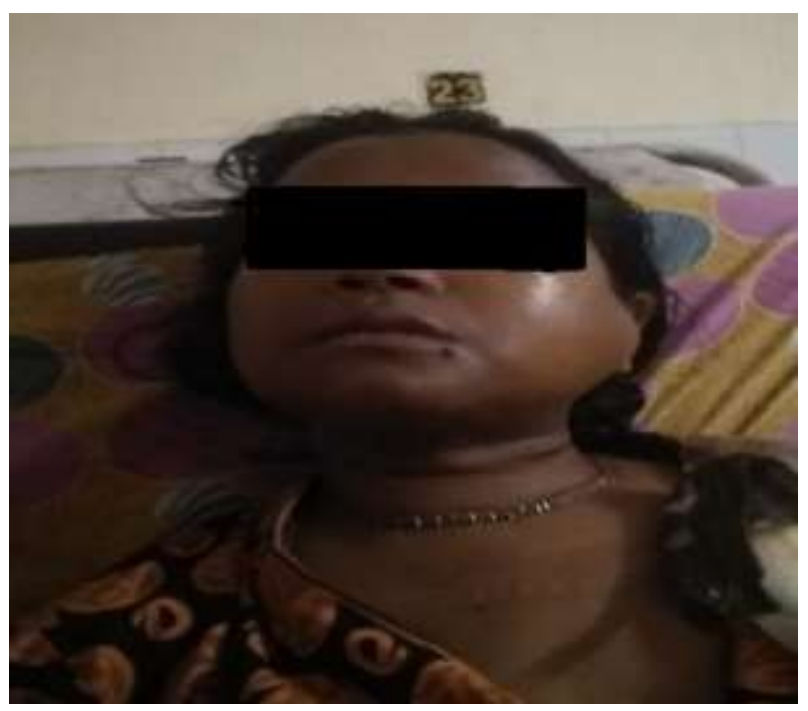

Figure 1: Young women with swelling over the left jaw with facial disfiguring. Generalized Debilitated patient 


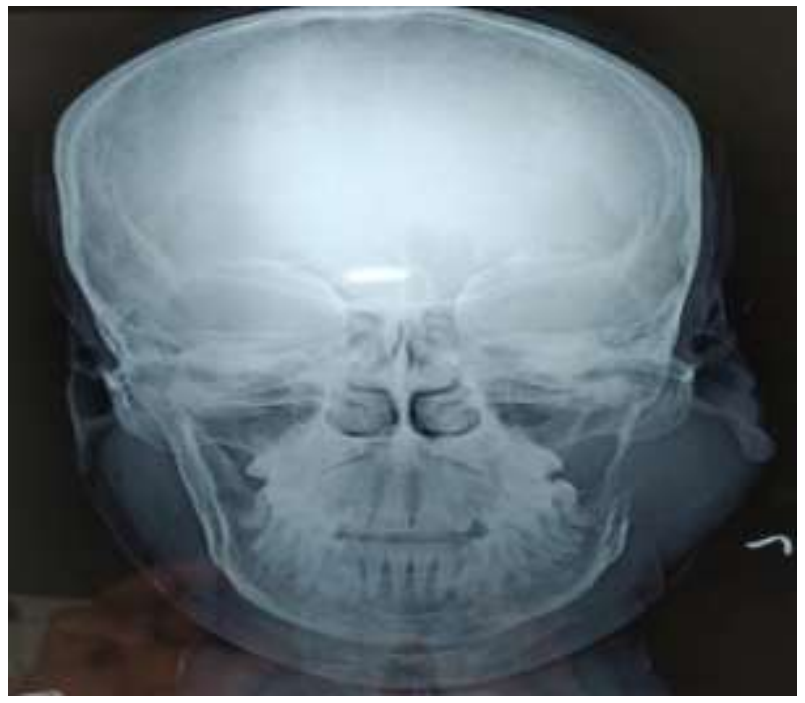

Figure 2: X-RAY Mandible AP View:

Multiloculated expansile lytic radiolucent lesion with left mandibular ramus destruction.

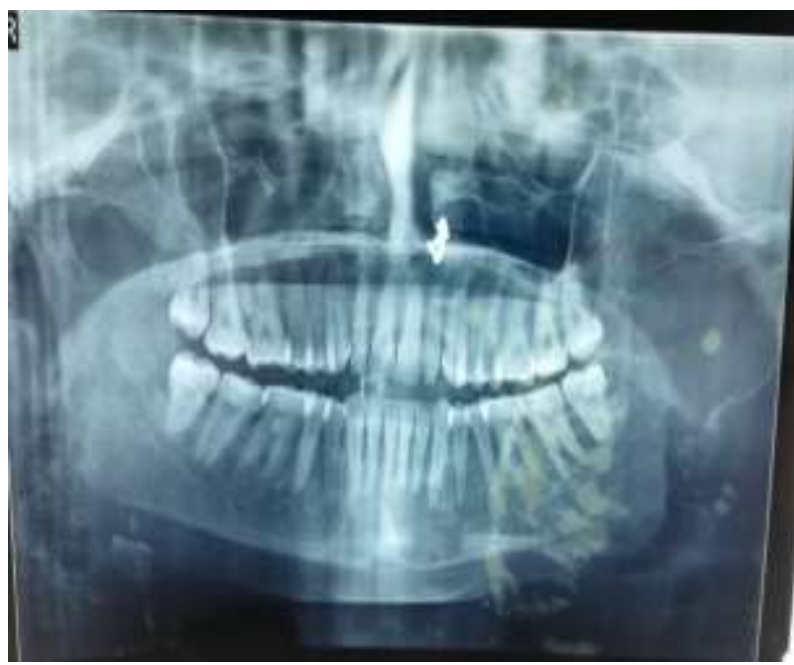

Figure 3: Panoramic view:

Multiloculated expansile lytic radiolucent lesion involving left mandibular ramus with destruction of the same. There is also resorption of lamina dura.

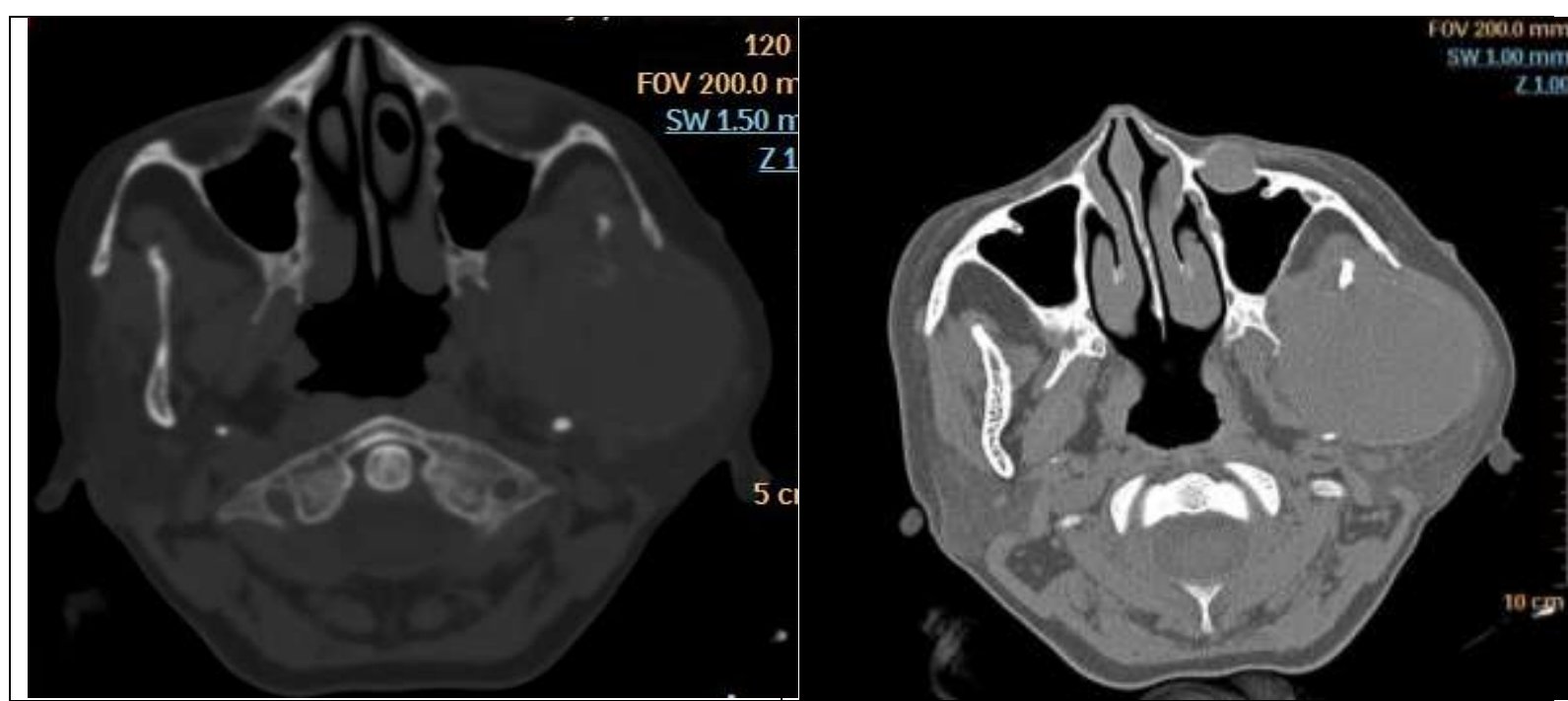

Figure 4 : Non Contrast Computed Tomography (NCCT) of Mandible axial section (Bone window) 
Expansile lytic lesion with large soft tissue involving left mandibular ramus extending medially up to left lateral pterygoid plates with mass effect and compression of pterygoid muscles. There is destruction of left mandibular ramus and condyle. Suggestive of Brown tumour of the mandible. Also note - Another small similar lesion involving the anterior wall of left maxillary sinus.

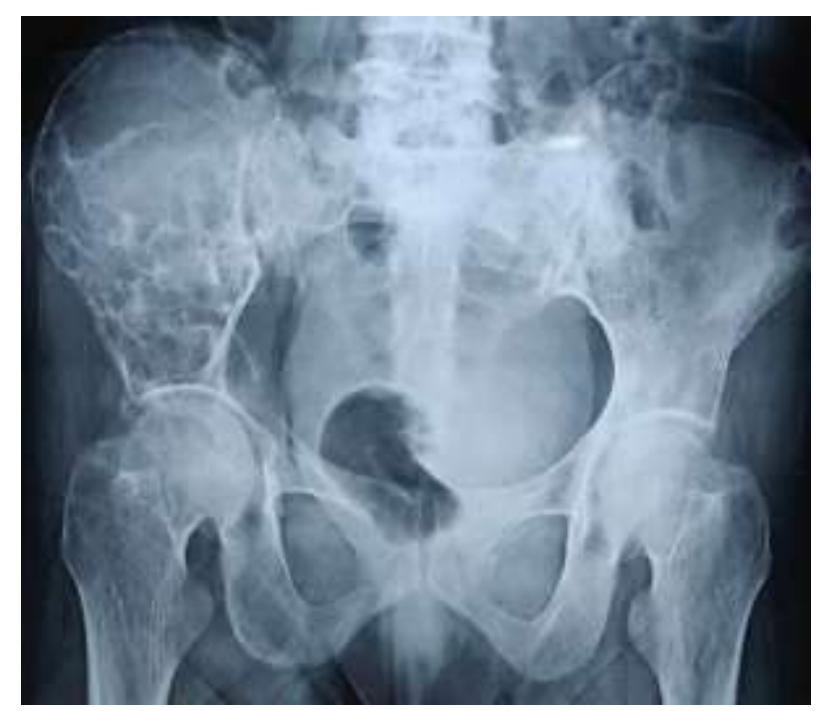

Figure 5: X-Ray pelvis with bilateral hip:

Multiloculated expansile lytic lesions involving the iliac wings suggestive of brown tumours.

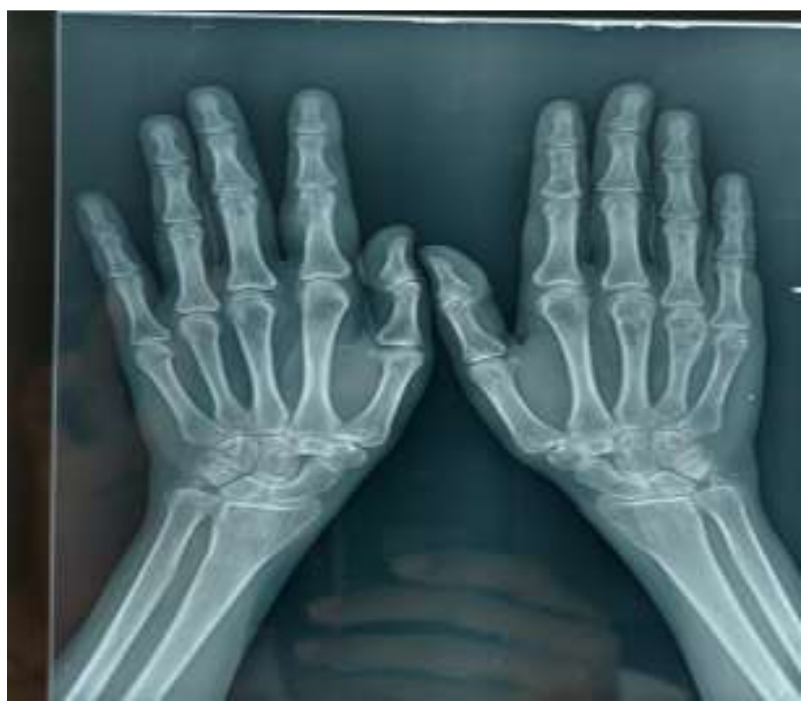

Figure 6: X - Ray bilateral hand AP view:

Early Terminal Tuft erosions - more pronounced in left $2^{\text {nd }}, 3^{\text {rd }}$ and $4^{\text {th }}$ phalanges. Subperiosteal erosion involving few phalanges, metacarpals. Brown tumours Expansile lytic lesions involving the right $3^{\text {rd }}$ and $4^{\text {th }}$ metacarpals, left $2^{\text {nd }}$ proximal and middle phalanges. Also note osteopenia of the bones. 


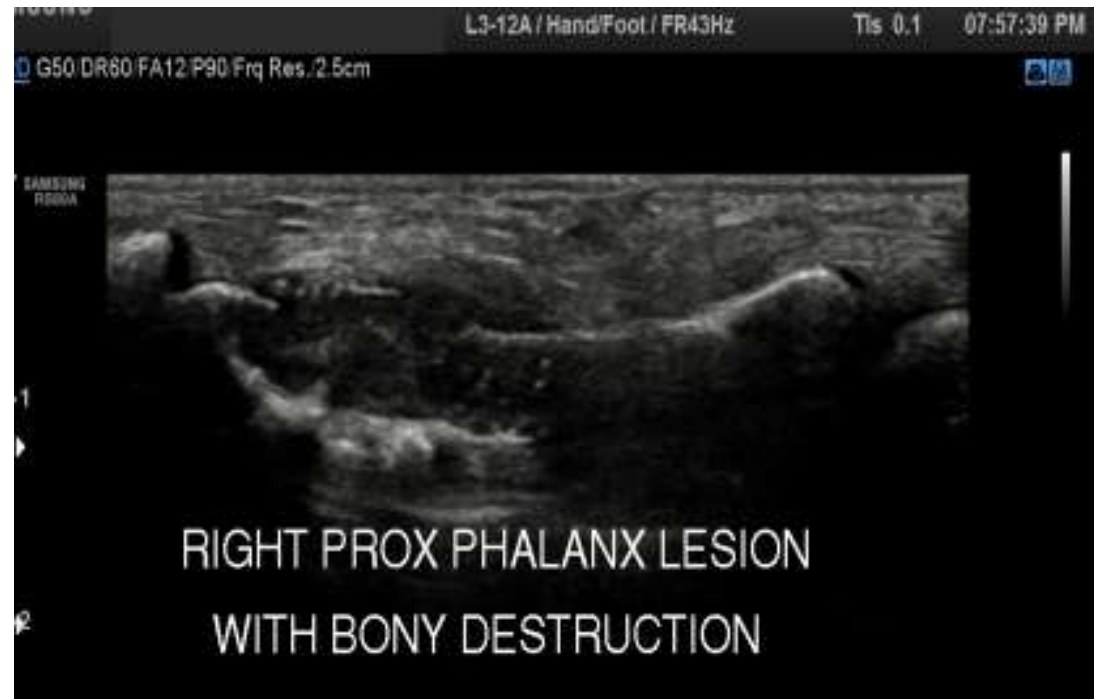

Figure 7: Corresponding USG of small joints of hands:

Showing soft tissue lesion in relation to right $4^{\text {rd }}$ metacarpal with cortical thinning and erosion.

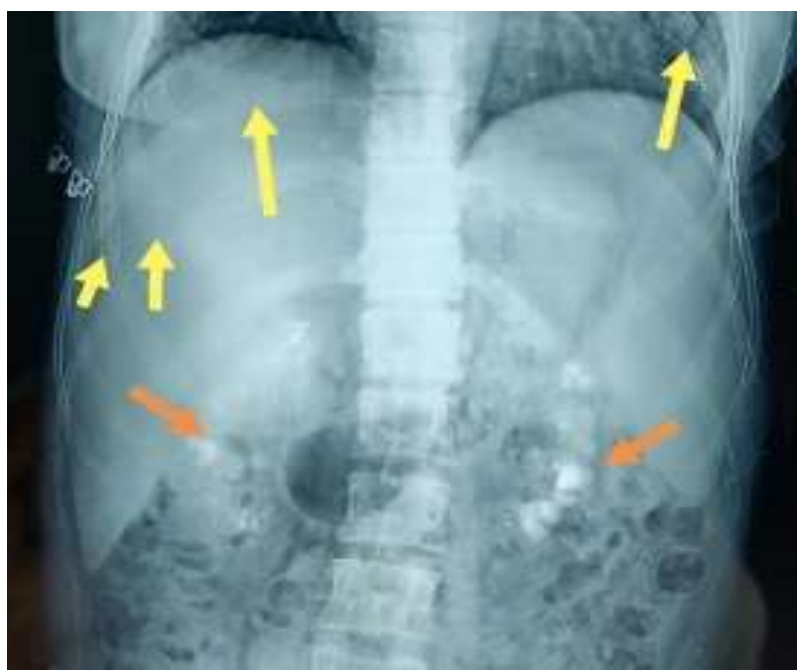

Figure 8: X- Ray PP Abdomen:

Multiple radio dense calculi in bilateral renal regions (Orange arrows)

Note - Focal expansile osteolytic lesions in multiple ribs bilaterally (Yellow arrows) and few ribs showing notching.

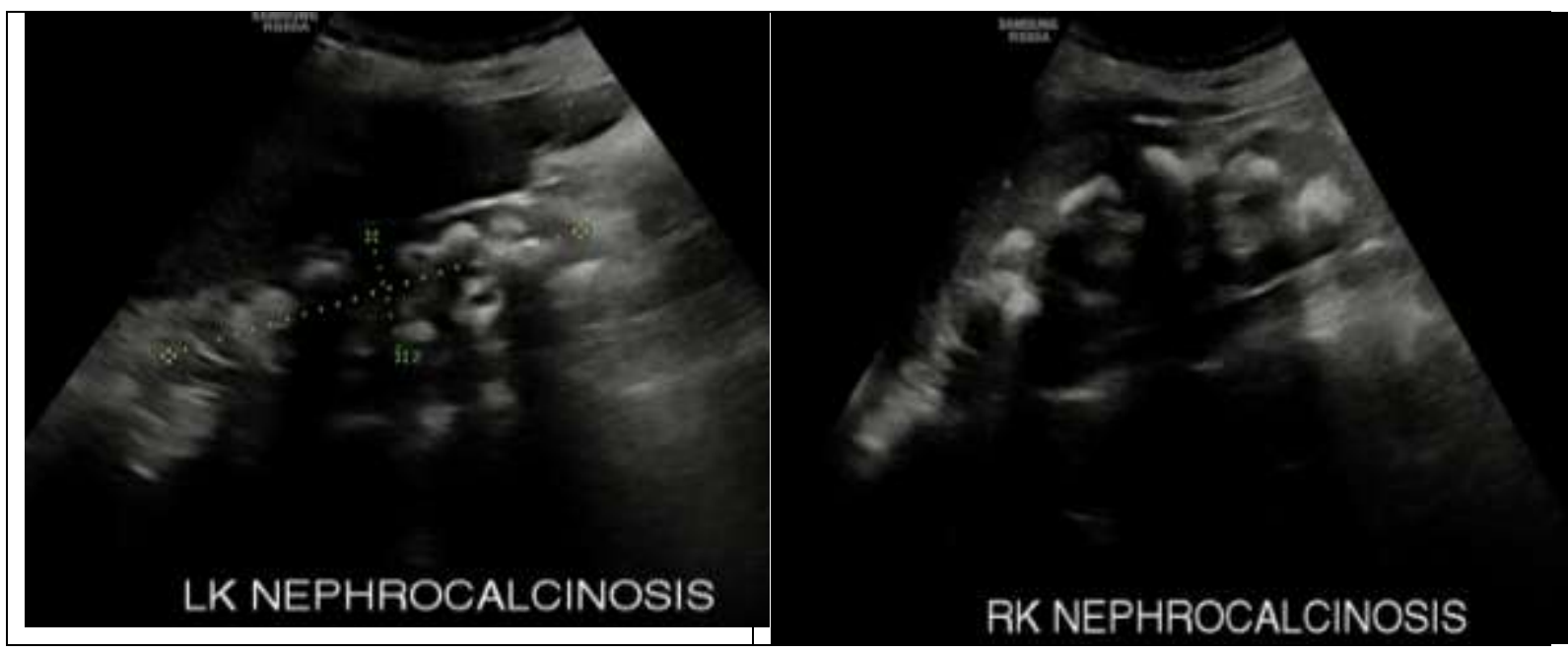

Figure 9: Corresponding USG of bilateral kidneys: 
Shows multiple hyperechoic calculi in all poles of medullary region of kidneys suggestive of BILATERAL MEDULLARY NEPHROCALCNOSIS

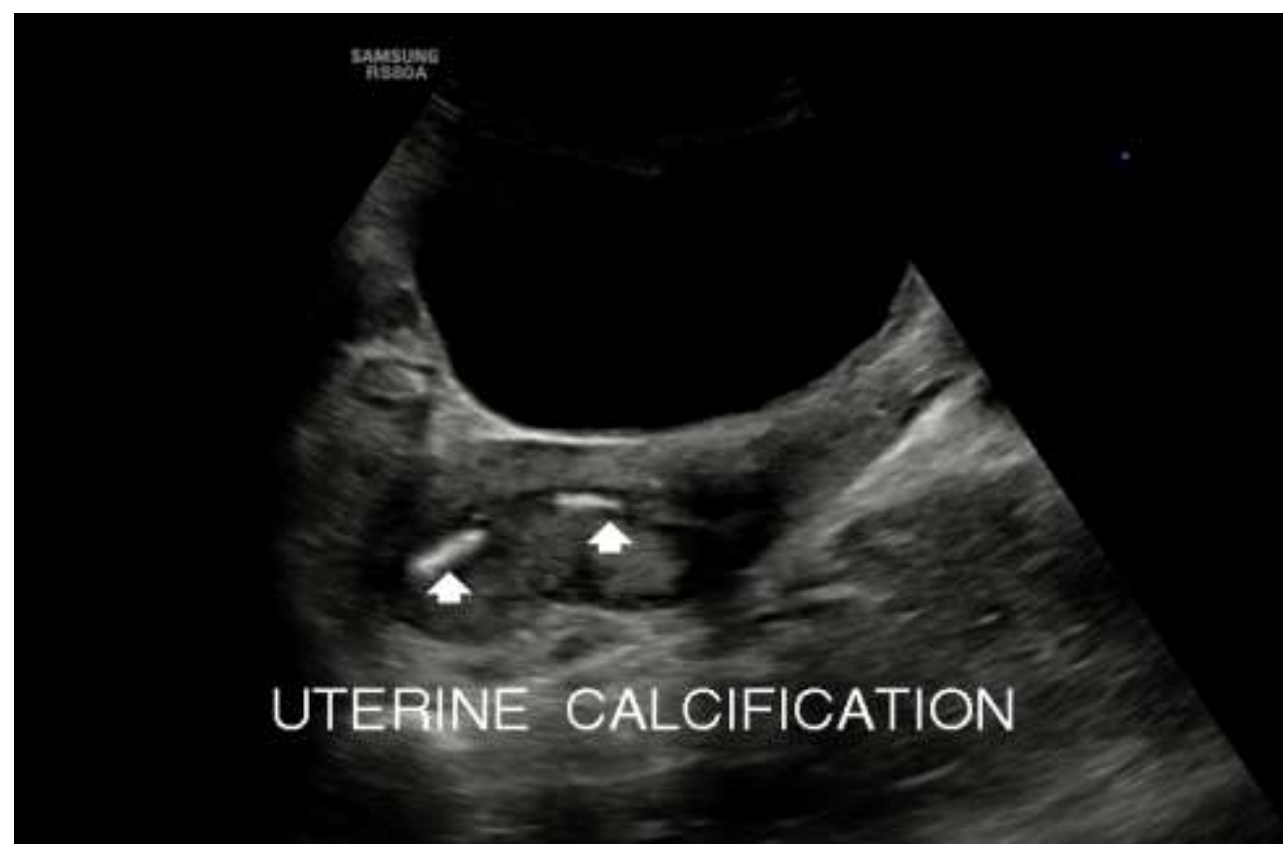

Figure 10: USG of Uterus:

Incidentally found calcific foci in endometrium of the uterus.

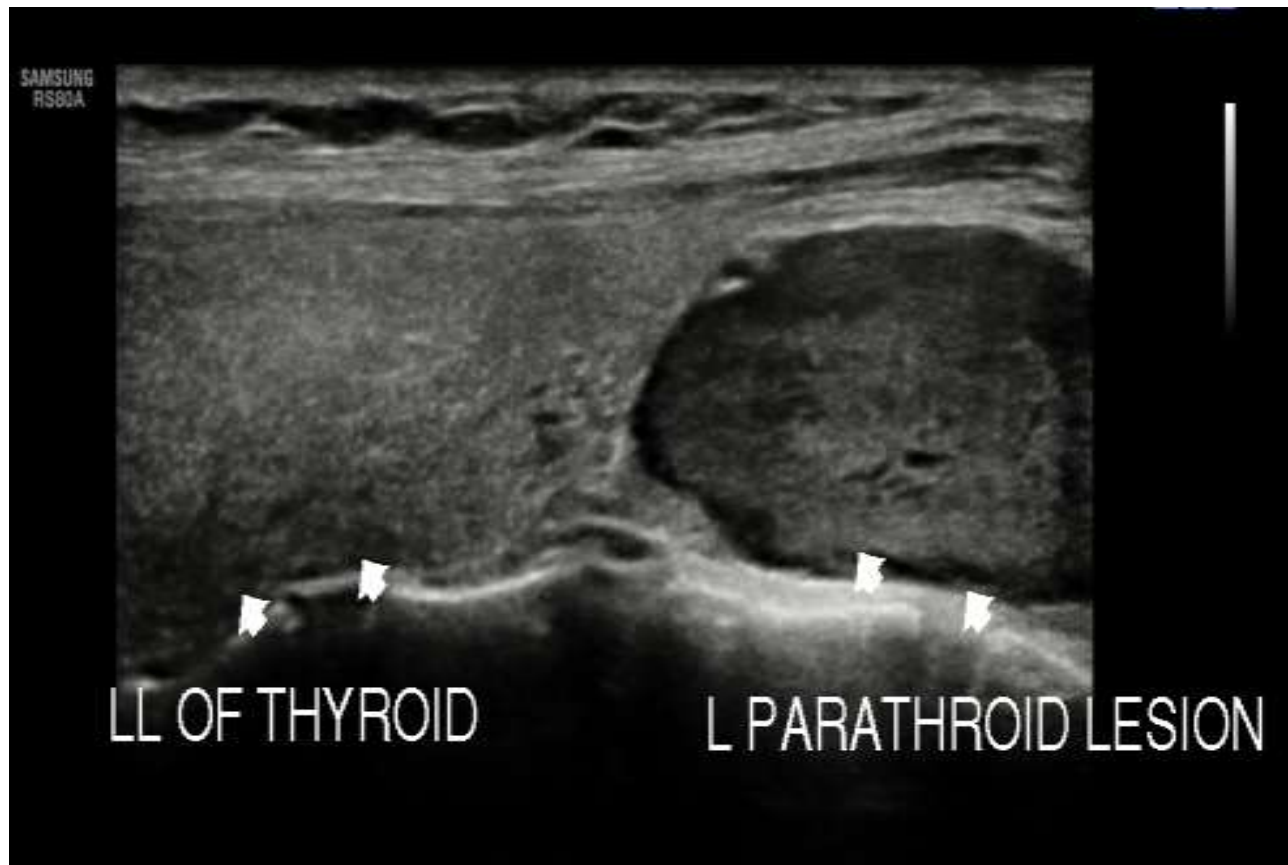

Figure 11: USG of thyroid

Hetero-echoic lesion inferior to left lobe of thyroid. Note- Bilateral thyroid glands showed normal morphology, size and vascularity. 


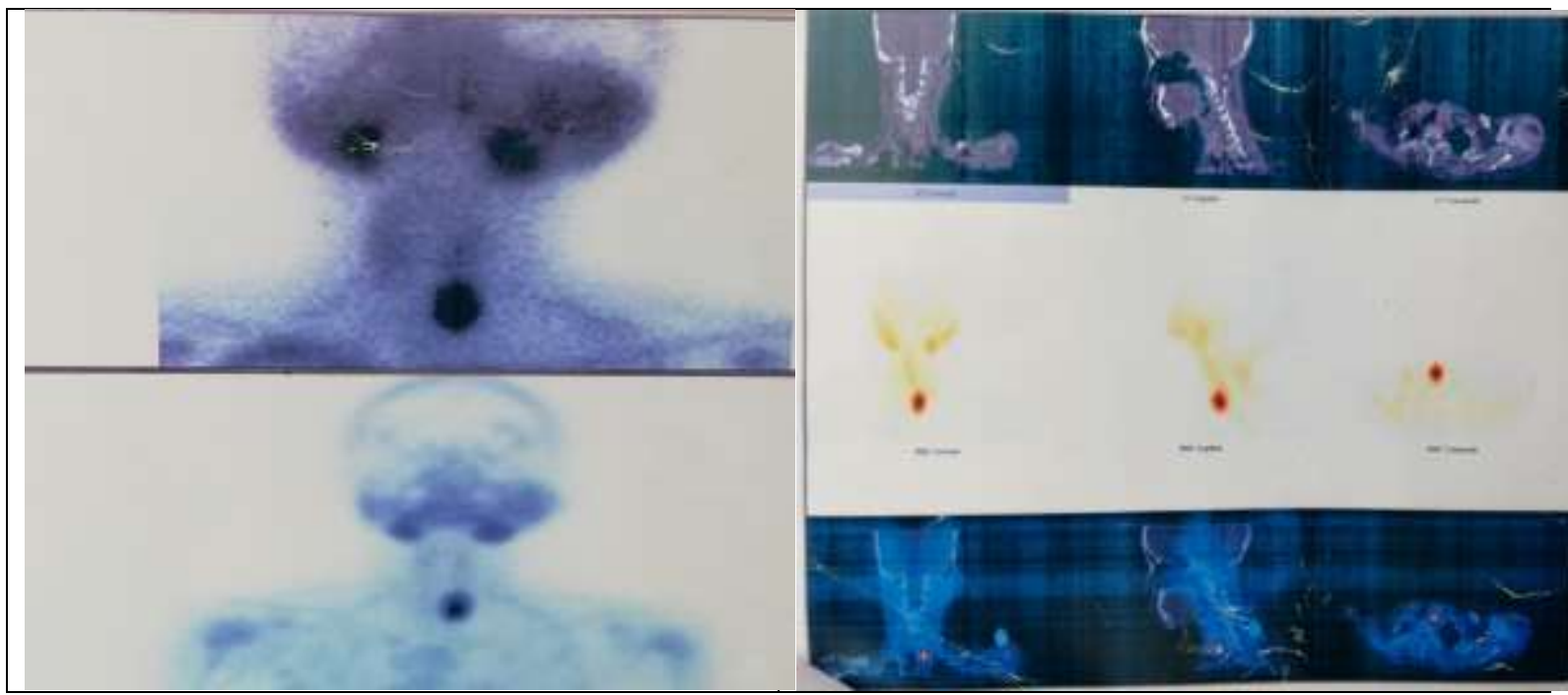

\section{Figure 12: ${ }^{99 m}$ Tc Sestamibi Scintiscan}

Abnormal focal tracer uptake, inferior to lower pole of the left thyroid lobe interpreted as parathyroid adenoma of left inferior parathyroid.

Note- ${ }^{99 \mathrm{~m}}$ Tc Sestamibi normally is distributed to the parotid and submandibular salivary glands, thyroid gland, heart, and liver; uptake is not seen in normal parathyroid glands.

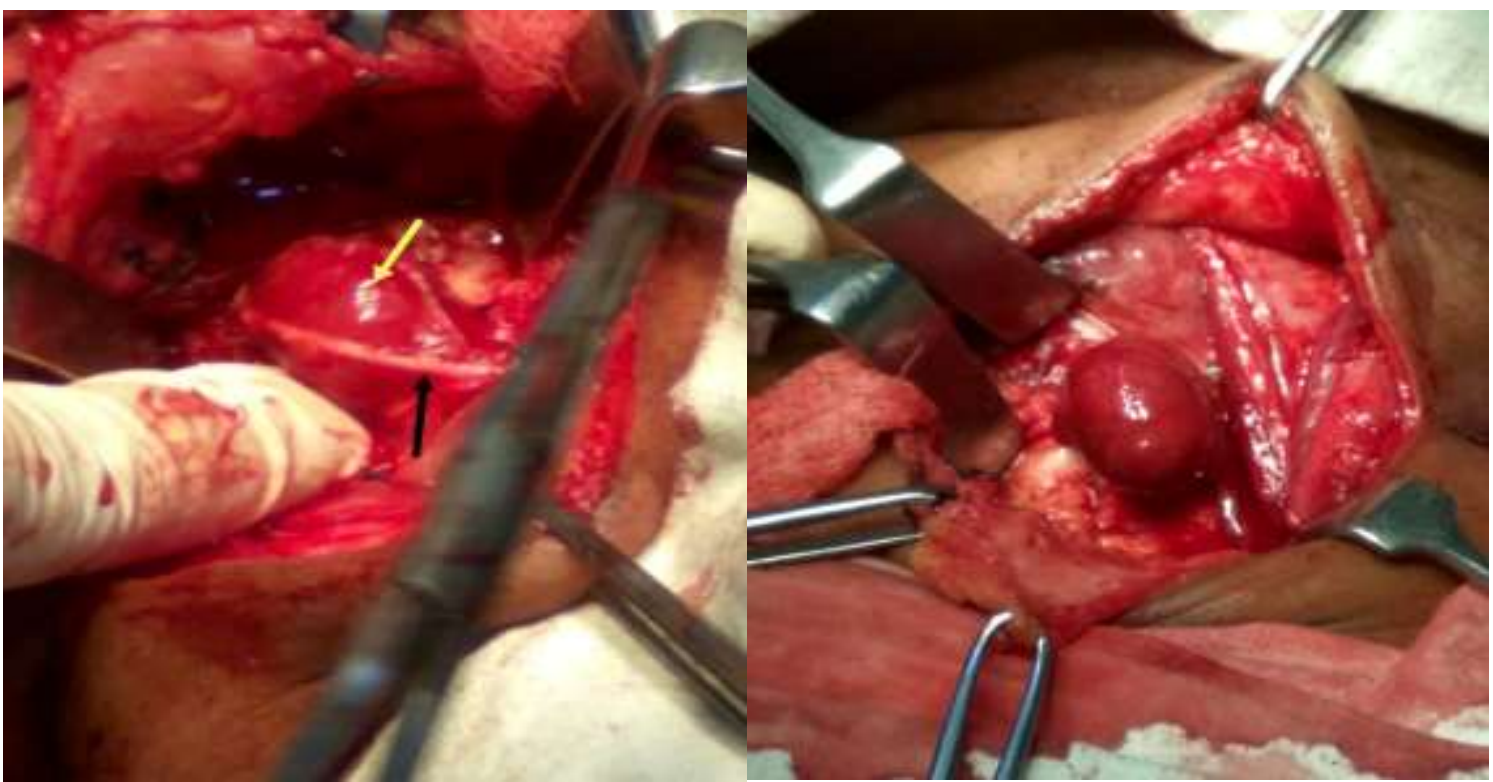

Figure 13: Intra-operative images:

One can appreciate the left inferior parathyroid adenoma (Yellow arrow), with left recurrent laryngeal (Black arrow) nerve traversing over the same. After dissecting and separating the recurrent laryngeal nerve from lesion, just before excision of parathyroid adenoma Note- Post operative period, retrospectively we asked the patient for any prior history of voice change/hoarseness of voice, however patient denied any such complaints. And also no voice change/hoarseness of voice was noted in post-operative period - ruling out iatrogenic RLN injury. 


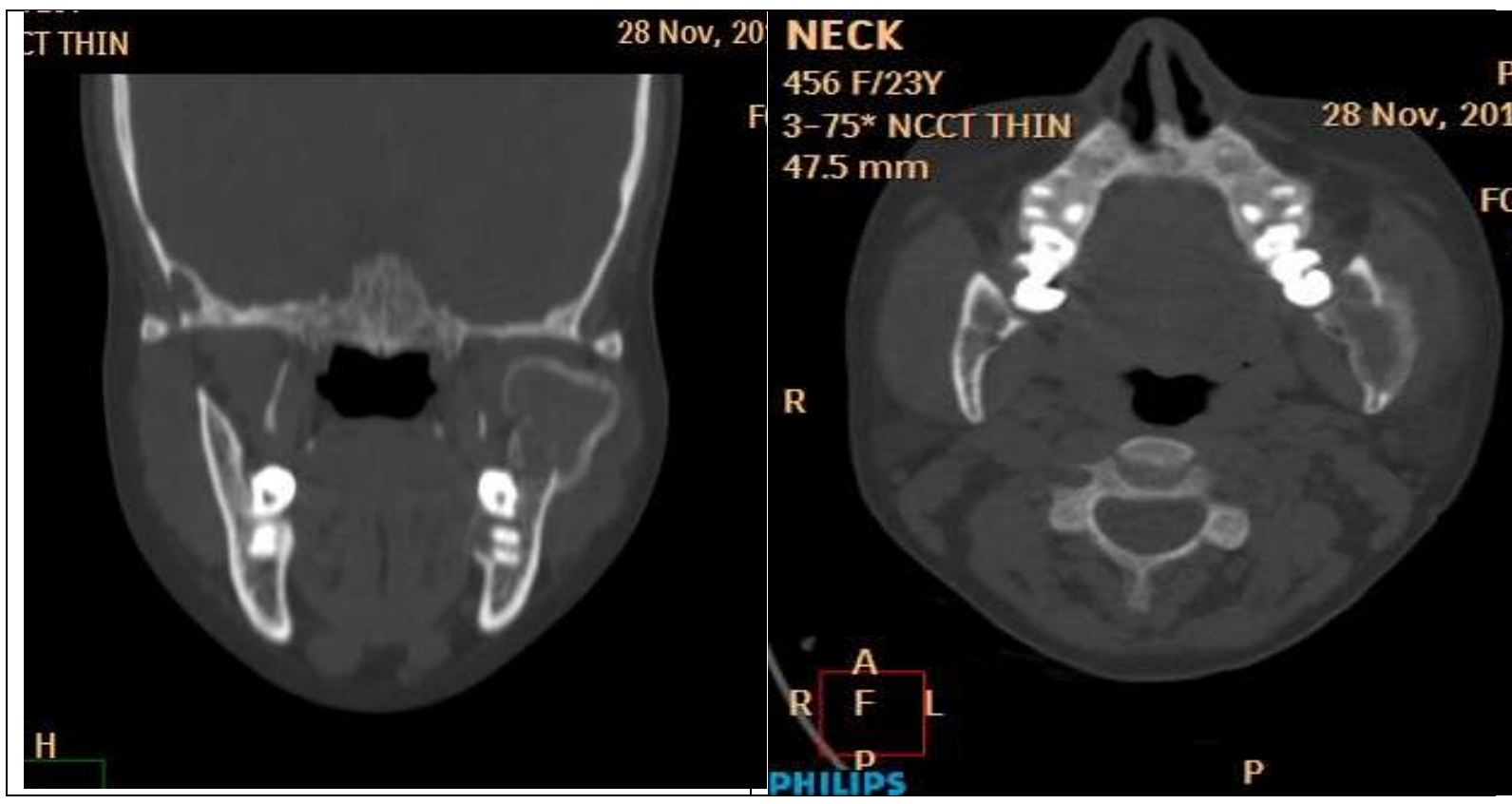

Figure 14 : NCCT Mandible (coronal and axial sections):

Significant reduction in size of brown tumour with remineralization at the site of the lesion - 6 month follow up image.

NOTE - Brown tumour of mandible was not operated, this shows spontaneous gradual regression of brown tumour after parathyroid adenectomy.

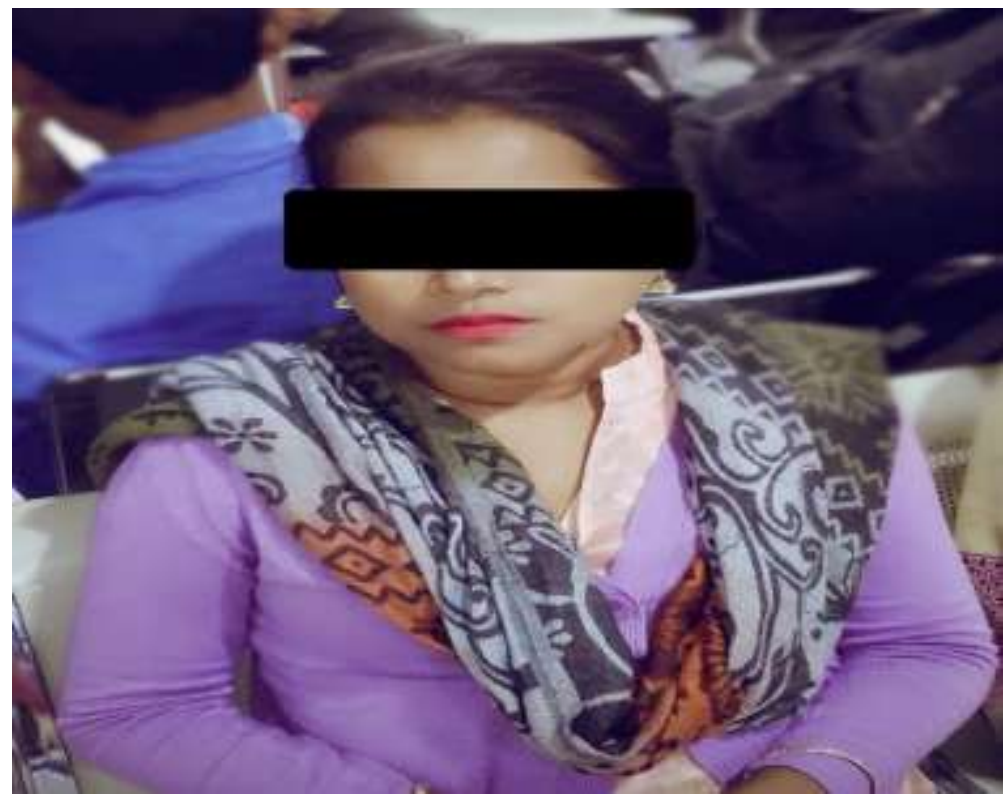

Figure 15: Improved General status of the patient with significant reduction in the size of the left jaw lesion without any facial disfiguring - Image taken at 6 month follow up visit.

\section{DISCUSSION}

Brown tumor also known as osteitis fibrosa cystica generalisata or Von Recklinghausen's disease of bone, is a metabolic bone disease that develops in primary, secondary or tertiary HPT. It should be differentiated from other true giant cell tumors of bone.

Brown tumors can occur in any location but are most common in the ribs, clavicle and pelvis. 
The reported prevalence of brown tumor is according to literature is less than $3 \%$ of patients suffering from primary hyperparathyroidism. And $1.5-1.7 \%$ in secondary hyperparathyroidism ${ }^{1}$ and can occur in mandible very rarely.

Furthermore, the frequency of occurrence is more among persons older than 50 years of age with a female to male ratio of $3: 1$.

This patient exhibited the classical symptoms of hypercalcemia that include "Painful bones (Hand bones, pelvis and mandible), renal stones (medullary nephrocalcinosis) and psychic moans (depression in this case)." However, patient presented for the first time only when the jaw tumor was increasing in size.

A routine skeletal survey revealed multiple bone involvement [2]; hence a metabolic etiology was suspected and hormonal analysis and other blood biochemistry was advised which showed raised alkaline phosphates and PTH levels of $1534 \mathrm{pg} / \mathrm{ml}$ (N: 12-65 pg/ml). Serum calcium level was $18.6 \mathrm{mg} / \mathrm{dl}(\mathrm{N}: 8.5-10.5 \mathrm{ml} / \mathrm{dl})$.

The FNAC of the jaw lesion showed vascular fibroblastic stroma and several osteoclast-like multinucleated giant cells suggesting possibility of brown tumour.

The FNAC of soft tissue lesion in the neck and Parathyroid scintigraphy confirmed the diagnosis of parathyroid neoplasia.

\section{Treatment}

Patient underwent complete excision of parathyroid adenoma - Curative Parathyroidectomy. The rest of the normal (3) parathyroid glands were left intact to maintain PTH levels in postoperative period.

In post-operative period, patient was on oral calcium and vit D3 to avoid hypocalcemia and later discontinued.

\section{Outcome and Follow-Up}

In immediate post-operative period, the patient was doing well, without any complications of surgery.

Despite high cure rate following parathyroidectomy, recurrence of primary hyperparathyroidism remains a clinical challenge and many may need second exploratory surgery, hence some studies recommend minimum 5 years of follow up [3].

- Patient was followed up every 6 monthlies after surgery and repeat imaging studies at sixth month revealed significant decrease in size of the brown tumor with bone remineralization, showing that Brown tumor resolves after successful excision of parathyroid adenoma. Patients general status was improved too. She could chew food easily now and also did not complain of tooth aches now. 
- However, the lesion was not disfiguring or symptomatic at 6 month follow up , hence surgical excision of brown tumour was not recommended [4,5]. Now we are following up the patient every 6 monthly.

- Even though the improvement of various diagnostic process and biochemical tests results in early diagnosis of HPT, the surgeons and radiologists should be alert of the possible occurrence of brown tumors in the jaws as first presentation of the previously undiagnosed patients.

\section{Differential Diagnosis}

○ Giant Cell tumour
$\circ$ Fibrous dysplasia
$\circ$ Multiple metastasis

\section{Learning Points}

- Brown tumour can be the first manifestation of hyperparathyroidism.

- Spontaneous regression of brown tumour is seen after removal of causative lesion (adenoma in this case) in primary hyperparathyroidism.

- Surgical excision of brown tumour is not recommended unless it is causing severe facial disfigurement and/or not resolving/ reducing in size after parathyroidectomy.

\section{ACKNOWLEDGMENT}

I would like to thank the faculty members and resident doctors of my department who has helped me throughout this case study and image diagnosis.

\section{REFERENCES}

1. Bahrami E, Alireza T, Ebrahim H, Mohammadreza S. Maxillary and orbital brown tumor of primary hyperparathyroidism. The American journal of case reports. 2012;13:183.

2. Resnick DL, Kransdorf MJ. Bone and joint imaging E-Book. Elsevier Health Sciences; 2004 Dec 15.

3. Lou I, Balentine C, Clarkson S, Schneider DF, Sippel RS, Chen H. How long should we follow patients after apparently curative parathyroidectomy?. Surgery. 2017 Jan 1;161(1):54-61.

4. Reséndiz-Colosia JA, Rodríguez-Cuevas SA, Flores-Díaz R, Juan MH, GallegosHernández JF, Barroso-Bravo S, Gómez-Acosta F. Evolution of maxillofacial brown tumors after parathyroidectomy in primary hyperparathyroidism. Head \& Neck: Journal for the Sciences and Specialties of the Head and Neck. 2008 Nov;30(11):1497-504.

5. Yucesoy T, Kilic E, Dogruel F, Bayram F, Alkan A, Akcan AC, Ozturk F. Spontaneous and Excellent Healing of Bilateral Brown Tumors in Mandible after Endocrinal 
Therapy and Subtotal Parathyroidectomy: Case Report with 4-Year Follow-Up. Case reports in dentistry. 2018;2018.

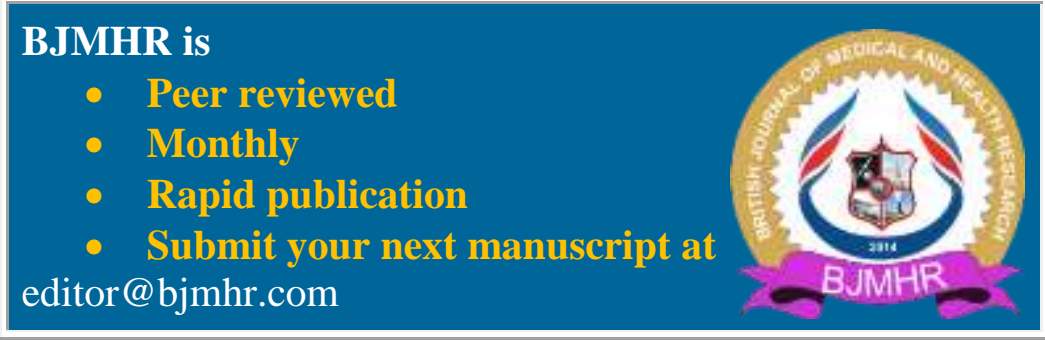

